\title{
Research Progress of Semi-Aromatic Copolyamides: Structure-Property Relationship
}

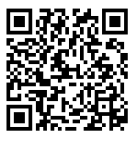

\author{
Hong Yin ${ }^{1}$, Yong Huang ${ }^{1}$, Jinbo Jia ${ }^{2}$, Zhirong Chen ${ }^{1}$, Shenfeng Yuan ${ }^{1 *}$, Hangjun Deng ${ }^{2}$ and Guiyang Zhou ${ }^{2}$ \\ ${ }^{1}$ College of Chemical and Biological Engineering, Zhejiang University, China
}

${ }^{2}$ Research Center, Zhejiang NHU Special Materials Co Ltd, China

Submission: July 30, 2020; Published: August 10, 2020

*Corresponding author: Shenfeng Yuan, College of Chemical and Biological Engineering, Zhejiang University, China

\begin{abstract}
Semi-aromatic copolyamides owing to both possessing the machinability of aliphatic polyamides and the high temperature resistance of aromatic polyamides, were widely used in automotive and electronic fields. To better summarizes the research on the structure-property relationship of semi-aromatic copolyamides, the review was carried out from three aspects: synthesis, structure characterization and structureproperty relationship. The study of structure-property relationship can be applied to the modification process of semi-aromatic copolyamides, and it can shed light on the design and actual production process.

Keywords: Copolyamides; Solution Polycondensation; Sequence structure; Structure-Property Relationship
\end{abstract}

\section{Introduction}

Semi-aromatic copolyamides contain both aliphatic and aromatic segments, therefore possess some unique properties, such as high mechanical strength, high temperature resistance, chemical corrosion resistance and excellent processing performance, etc., and were widely used in automobile and electronic industry. Researchers have done a lot to improve the properties of semi-aromatic copolyamides like widen the melt processing window, enhance mechanical strength and heat resistance, so that the product can be used in harsher working environment $[1,2]$. The structure of semi-aromatic copolyamides has an important effect on its properties, and so changing the chain structure has become one of the important methods to improve the properties of copolyamides, and the nuclear magnetic resonance (NMR) is an important means to characterize the sequence structure [3]. In recent years, semi-aromatic copolyamides exhibit great advantages in the field of special engineering plastics, and the microstructure design of copolyamides was widely used to enhance the product performance [4].

\section{Discussion}

\section{Synthesis Method}

The mainly synthesis method of semi-aromatic copolyamides is solution polycondensation method, which is beneficial to enhance the heat and mass transfer in the polymerization process, and the reaction is highly controllable. The solution polycondensation method can be divided into low temperature and high temperature according to the polymerization temperature. The high temperature solution polycondensation method adopts nylon salt solution for polymerization, and the production process is mature and stable $[5,6]$. However, due to the serious chain exchange and chain transfer in high temperature polycondensation process, it is difficult to synthesize copolyamides with specific sequence structure. Low temperature solution polycondensation method uses highly active acyl chloride and diamines dissolved in organic solvent, the reaction rate is fast and generates a lot of heat, in order to avoid side reactions, it is necessary to react in low temperature without oxygen [7].

\section{Characterization Method}

NMR is the main method to characterize the sequence structure of copolyamides. Geert et al. [8] dissolved polyamides in solvents such as D2SO4, TFA and HFIP etc., and used 1H-NMR to distinguish various homopolyamides qualitatively. 13C-NMR analysis was used to obtain the peak position of methylene of a series of homopolyamides in the above solvents. 13C-NMR and 15N-NMR can distinguish the mixture of homopolyamides, and the different sequence structure of copolyamides. However, due to the occurrence of chain exchange and chain transfer in the polycondensation process, the synthesized copolyamides 
commonly contain random chain segments, and the poor solubility of the copolyamides result in the unclear NMR peak $[9,10]$.

\section{Structure-property Relationship}

The microstructure of chain segment of semi-aromatic copolyamides determines the properties of the product, and the design of the molecular structure is conducive to obtaining the corresponding target product. The regularity of the aliphatic segments on the main chain has a great influence on the crystallization properties, and chain segments containing the cis conformation unit are arranged more closely and the degree of crystallinity is better. So that the thermal stability and melt flow properties of the copolyamides with the cis conformation unit are better than those with the trans unit conformation [11]. The benzene ring in the chain segment plays a role in improving the heat resistance and reducing the crystallization property of the copolyamides. Therefore, by increasing the amount of terephthalic acid in the reaction process, the crystallization degree of the copolyamides is reduced, which is conducive to obtaining transparent copolyamides with better mechanical strength [12]. The terephthalic acid units in the chain segment will reduce the processing performance of the copolyamides. Adding asymmetric isophthalic acid units to the chain segment can obtain amorphous segments and improve the melt flow performance of the copolyamides [13].

\section{Conclusion}

As a copolycondensation product of aliphatic polyamides and aromatic polyamides, semi-aromatic copolyamides have the characteristics of both. The study of structure-property relationship has inspiring significance for the design on the microstructure of the chain segment and was widely used in the study of the modification process of semi-aromatic copolyamides. The segment design was mostly realized by introducing monomers with specific structure, which has strong controllability. However, due to the severe side reactions in the polymerization process, it is difficult to achieve industrial production of semi-aromatic copolyamides with specific sequence structure. In the foreseeable future, the improvement of synthesis methods and the enhancement of detection technology will facilitate the in-depth study of the structure-property relationship of semi-aromatic copolyamides and deepen the understanding of the micro-design of high-performance composite materials.

\section{Acknowledgment}

Financial support of the Zhejiang Provincial Key Research and Development Plan-development and industrialization of high performance semi-aromatic nylon (PA6T) with grant number 2019 C01103.

\section{References}

1. Zou G, Wang P, Feng W, Ji J, Ren Z (2018) Poly(decamethylene terephthalamide) copolymerized with long-chain alkyl dodecanedioic acid: Toward bio-based polymer and improved performances. Applied Polymer 135(31): 46531.

2. Qu C, Tang $Y$, Wang D, Fan X, Kai S, et al. (2020) Improved processability of PA66-polyimide copolymers with different polyimide contents. Journal of applied polymer science: 49640.

3. Porfyris A, Vouyiouka S, Papaspyrides C, Ruud (2016) Investigating alternative routes for semi-aromatic polyamide salt preparation: The case of tetramethylenediammonium terephthalate (4T salt). Journal of Applied Polymer Science 133(13): 42987.

4. Djukic S, Bocahut A, Bikard J, Long D (2020) Mechanical properties of amorphous and semi-crystalline semi-aromatic polyamides. Heliyon 6(4): e3857.

5. Papaspyrides CD, Porfyris AD, Rulkens R, Kolkman AJ, Grolman E (2016) The effect of diamine length on the direct solid state polycondensation of semi-aromatic nylon salts. Journal of Polymer Science Part A: Polymer Chemistry 54(16): 2493-2506.

6. Zhang C L, Wan L, Gu X P, Feng L (2015) A Study on a Prepolymerization Process of Aromatic-Contained Polyamide Copolymers PA(66-co-6T) via One-Step Polycondensation. Macromolecular Reaction Engineering 9(5): 512-521.

7. Taherian S, Rahmani S, Sharif A, Ahmad Z, Mahdi A (2019) In-situ polymerization of aliphatic-aromatic polyamide nanocomposites in the presence of Halloysite nanotubes. Polymers for advanced technologies 30(3): 538-544.

8. Velden G, Beulen J, de Keijzer H (1991) Review of 1H- and 13C-NMR data on homo-, co- and terpolyamides in solution[J]. Recueil des Travaux Chimiques des Pays-Bas 110(12): 516-525.

9. Bakkali Hassani C, Planes M, Roos K, Anne L, Emmanuel I, et al. (2018) Synthesis of polyamide 6 with aramid units by combination of anionic ring-opening and condensation reactions. European Polymer Journal 102: 231-237.

10. Qi X, Wang W, Zhang J, Zhu Y, Zhang F (2018) Aqueously soluble semiaromatic copolyamides with dual-functional groups as sizing agent. Journal of applied polymer science 136(9): 47132.

11. Zhang G, Yan G, Ren H (2016) Effects of a trans - or cis -cyclohexane unit on the thermal and rheological properties of semi-aromatic polyamides. Polymer Chemistry 7: 44-53.

12. Peng S, Peng L, Yi C, Wei Z, Xi W (2018) A novel synthetic strategy for preparing semi-aromatic components modified polyamide 6 polymer[J]. Journal of polymer science. Part A, Polymer chemistry 56(9): 959-967.

13. Guo J, Li H, Xue B, Zhu D, Zhang X, et al. (2020) A synthesized semiaromatic copolyamaide through synergy of three different kinds of monomers: Toward high transparency, excellent heat resistance and melt flowing property. Journal of applied polymer science: 49678. 
(C) This work is licensed under Creative DOI: 10.19080/AJOP.2020.04.555638

\section{Your next submission with Juniper Publishers will reach you the below assets}

- Quality Editorial service

- Swift Peer Review

- Reprints availability

- E-prints Service

- Manuscript Podcast for convenient understanding

- Global attainment for your research

- Manuscript accessibility in different formats

( Pdf, E-pub, Full Text, Audio)

- Unceasing customer service

Track the below URL for one-step submission https://juniperpublishers.com/online-submission.php 